В.П. Максименко, к.т.н.,ГП НИИСП г.Киев;

В.А. Крицкий, к.т.н., ГНТЦ ЯРБ;

B.О. Посох, ведущий инж., ГП "ДНИЦ СКАР"

\title{
ОЦЕНКА ЕФФЕКТИВНОСТИ РЕЗИНОВЫХ ДЕМПФЕРОВ ПРИ СОУДАРЕНИИ ЕЛЕМЕНТОВ ОБОРУДОВАНИЯ
}

\begin{abstract}
Аннотация. Проведена оценка эффективности использования резиновых демпферов для уменьшения сейсмических воздействий на элементы оборудования. Жесткостные характеристики резиновых демфирующих прокладок определены при помощи программы "Характеристики резино-металлического демпфера" в ЭСПРИ-2018.
\end{abstract}

Ключевые слова: резиновые демпферы.

При эксплуатации различного оборудования в атомных, тепловых электростанциях и других промышленных объектах не всегда удается обеспечить необходимое безопасное расстояние между элементами запорной арматуры и коммуникациями для исключения их соударения, что может привести к развитию внештатных ситуаций [1, 2 ].

В данной работе предлагается проверить эффективность использования резиновых, резино-металлических и силиконовых прокладок для уменьшения ударных и сейсмических воздействий на элементы оборудования

Для определения расчетных характеристик, коэффициентов постели демпферов используется программа "Характеристики резинометаллического демпфера" в ЭСПРИ-2018 [3]. В программе исходя из расчетных нагрузок и размеров демпфера определяются коэффициенты постели, модули статической упругости и предельно допустимые нагрузки. Полученные характеристики, такие как: статическую жесткость на сжатие $-\mathrm{C}_{\mathrm{z}}$ и сдвиг $-\mathrm{C}_{\mathrm{x}}$; коэффициент диссипации энергии $-\psi$ и др. будут использованы в ПК "ЛИРА САПР" при моделировании соударения элементов трубопроводов, арматури и др. для оценки эффективности использования демпфирующих прокладок. Вид рабочего окна программы приведен на Рис.1.

Расчет сплошных и полых цилиндрических сейсмоблоков (СБ) следует производится на сжатие и сдвиг. Основные параметрвы СБ: d - диаметр по резиновому элементу; $h$ - высота (толщина) резинового элемента в целом; $\mathrm{C}_{\mathrm{z}}-$ статическую жесткость на сжатие $\left(\mathrm{C}_{\mathrm{n}}\right)$ и сдвиг $-\mathrm{C}_{\mathrm{x}}\left(\mathrm{C}_{\tau}\right) ; \psi-$ коэффициент диссипации энергии.

Определяются вертикальные и горизонтальные коэффициенты постели $\mathrm{C}_{\mathrm{Z}}, \mathrm{C}_{\mathrm{x}}-$ отвечающие по

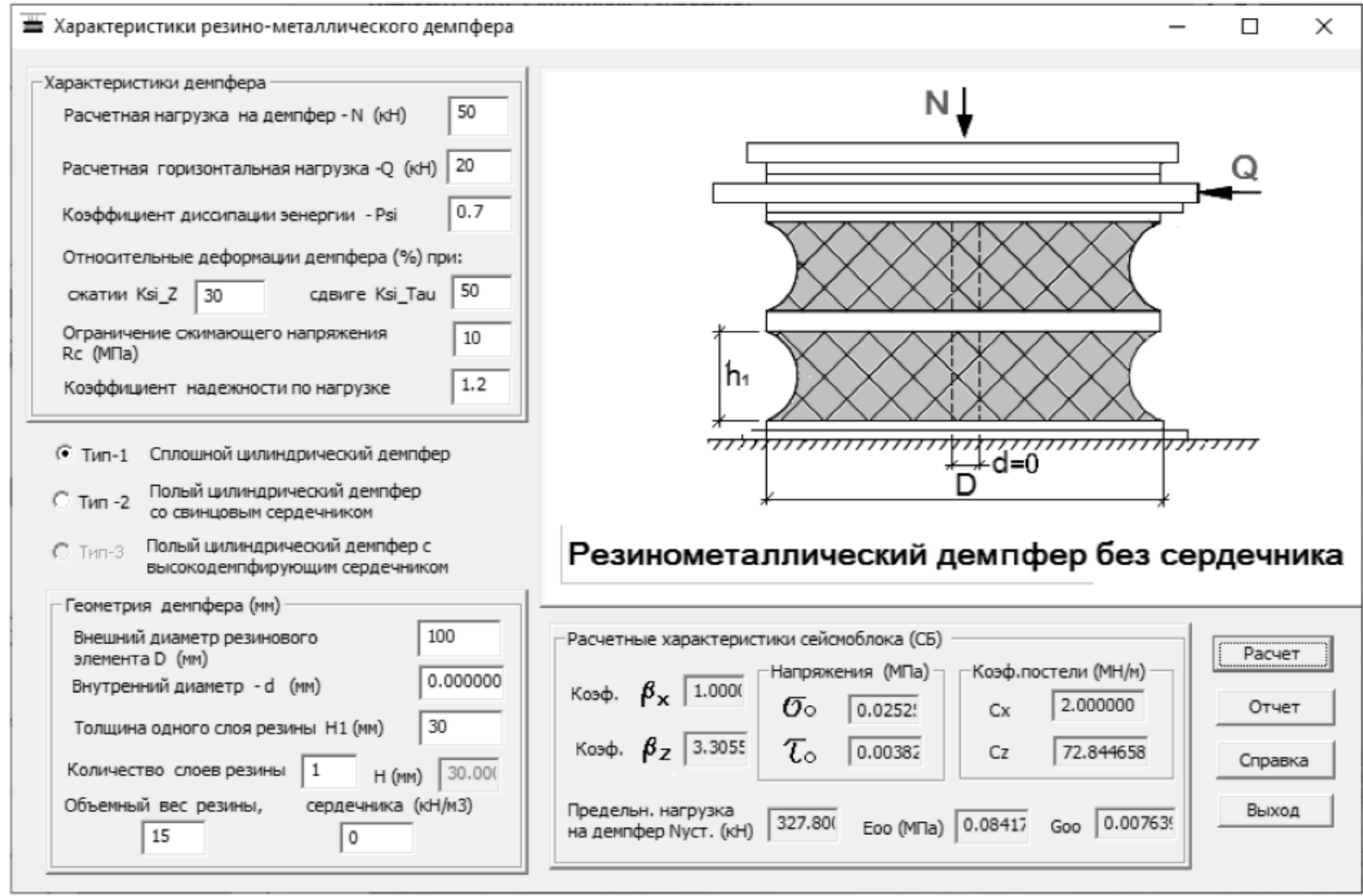

Рис.1 Вид рабочего окна программы "Характеристики резинометаллического демпфера" 
Табл. 1. Характеристики демпфирующих прокладок

\begin{tabular}{|c|c|c|c|c|c|c|c|c|c|}
\hline $\begin{array}{l}\text { Диаметр } \\
\text { D (мм) } \\
\text { Привед. } \\
\text { bxh }\end{array}$ & $\begin{array}{l}\text { Площадь } \\
\left(\text { мм }^{2}\right)\end{array}$ & $\begin{array}{l}\text { Толщина } \\
\text { слоя } \\
\text { (мм) }\end{array}$ & $\begin{array}{l}\text { Расчетн. } \\
\text { нагрузка } \\
\mathrm{N}, \mathrm{Q} \\
\text { (кН) }\end{array}$ & $\begin{array}{l}\text { Жестк. на } \\
\text { сжатие Cz } \\
\text { мH } \backslash \text {, } \\
(\mathrm{Tc} \backslash \mathrm{M})\end{array}$ & $\begin{array}{l}\text { Жестк.на } \\
\text { сдвиг Сх } \\
\mathrm{MH} \backslash \mathrm{M}, \\
(\mathrm{Tc} \backslash \mathrm{M})\end{array}$ & $\begin{array}{l}\text { Модуль } \\
\text { сжатия } \\
\mathrm{E}_{\infty} \\
\text { МПа }\end{array}$ & $\begin{array}{l}\text { Модуль } \\
\text { сдвига } \\
\mathrm{G}_{\infty} \\
\text { МПа } \\
\end{array}$ & $\begin{array}{l}\text { Предельн. } \\
\text { нагрузка } \\
\text { Nуст. } \\
(\text { кH), (тс) }\end{array}$ & $\begin{array}{c}\text { Предел. } \\
\text { деформ. } \\
\text { dz, dx } \\
\text { (мм) }\end{array}$ \\
\hline $\begin{array}{l}100.0 \\
80 \times 98.2\end{array}$ & 7853.98 & 30.0 & $\begin{array}{l}50.0 \\
20.0 \\
\end{array}$ & $\begin{array}{l}72.845 \\
(7428.12)\end{array}$ & $\begin{array}{l}2.0 \\
(203.95)\end{array}$ & 0.08417 & 0.00764 & $\begin{array}{l}327.8 \\
33.43 \\
\end{array}$ & $\begin{array}{c}9.0 \\
15.0\end{array}$ \\
\hline $\begin{array}{l}100.0 \\
80 \times 98.2\end{array}$ & 7853.98 & 30.0 & $\begin{array}{l}100.0 \\
20.0\end{array}$ & $\begin{array}{l}145.689 \\
(14856.2)\end{array}$ & $\begin{array}{l}4.0 \\
(407.89)\end{array}$ & 0.16835 & 0.01529 & $\begin{array}{l}655.6 \\
66.85 \\
\end{array}$ & $\begin{array}{c}9.0 \\
15.0 \\
\end{array}$ \\
\hline $\begin{array}{l}100.0 \\
80 \times 98.2\end{array}$ & 7853.98 & 30.0 & $\begin{array}{l}200.0 \\
50.0\end{array}$ & $\begin{array}{l}291.379 \\
(29712.5)\end{array}$ & $\begin{array}{l}8.0 \\
(815.78)\end{array}$ & 0.16835 & 0.01529 & $\begin{array}{l}655.6 \\
66.85 \\
\end{array}$ & $\begin{array}{c}9.0 \\
15.0 \\
\end{array}$ \\
\hline $\begin{array}{l}79.789 \\
50 \times 100\end{array}$ & 5000.0 & 30.0 & $\begin{array}{l}200.0 \\
50.0\end{array}$ & $\begin{array}{l}291.379 \\
(29712.5)\end{array}$ & $\begin{array}{l}8.0 \\
(815.78)\end{array}$ & 0.3367 & 0.03056 & $\begin{array}{l}1311.2 \\
133.71\end{array}$ & $\begin{array}{c}9.0 \\
15.0 \\
\end{array}$ \\
\hline $\begin{array}{l}79.789 \\
50 \times 100\end{array}$ & 5000.0 & 30.0 & $\begin{array}{l}100.0 \\
20.0\end{array}$ & $\begin{array}{l}12.457 \\
(1270.26)\end{array}$ & $\begin{array}{l}2.0 \\
(203.94)\end{array}$ & 0.10935 & 0.0240 & $\begin{array}{l}120.0 \\
12.85\end{array}$ & $\begin{array}{l}18.0 \\
30.0 \\
\end{array}$ \\
\hline $\begin{array}{l}79.789 \\
50 \times 100\end{array}$ & 5000.0 & 20.0 & $\begin{array}{l}100.0 \\
20.0 \\
\end{array}$ & $\begin{array}{l}33.33 \\
(3398.64)\end{array}$ & $\begin{array}{l}3.0 \\
(305.92)\end{array}$ & 0.14604 & 0.0240 & $\begin{array}{c}199.97 \\
20.0\end{array}$ & $\begin{array}{l}12.0 \\
20.0\end{array}$ \\
\hline
\end{tabular}

смыслу жесткости на 1пм нуль-элементов №56 в ПК "ЛИРА-САПР" и др.

Расчет коэффициентов постели сплошных цилиндрических СБ производится по следующим формулам $\left(\mathrm{C}_{\mathrm{z}}=\mathrm{C}_{\mathrm{n}}, \mathrm{C}_{\mathrm{x}}=\mathrm{C}_{\tau}, \mathrm{U}_{\mathrm{z}}\right)$ :

- на сжатие:

$$
C_{n}=\beta_{n} \frac{\pi R^{2} E_{\infty}}{h}, \beta_{n}=1+0,83\left(\frac{R}{h}\right)^{2},
$$

- на сдвиг

$$
C_{\tau}=\beta_{\tau} \frac{\pi R^{2} G_{Q}}{h} ; \beta_{\tau} \approx 1,0,
$$

Для численного моделирования работы демпферов при статических и сейсмических нагрузках во времени определяется: статический (условно-равновесный) модуль Юнга - Е но-равновесный) модуль сдвига $-\mathrm{G}_{\infty}$ в виде:

$$
E_{\infty}=\frac{\beta P_{\infty} h}{F \Delta}, \quad G_{\infty}=\frac{P_{\infty} h}{2 F \Delta},
$$

где $\mathrm{P}_{\infty}-$ значение деформирующей силы; $\mathrm{F}-$ площадь сжатия; $\Delta$ - деформация резинового элемента (мм); $\beta$ - коэффициент ужесточения на торцах.

Приняты следующие обозначения: $\mathrm{C}_{\mathrm{n}}, \mathrm{C}_{\tau}-$ жесткость СБ при вертикальной нагрузке и сдвиге; $\beta_{\mathrm{n}}, \beta_{\tau}-$ коэффициенты ужесточения на торцах (их значения табулированы); $\mathrm{R}$ - радиус сплошного СБ; $\mathrm{R}_{1}, \mathrm{R}_{2}-$ соответственно внешний и внутренний радиусы полого СБ.

Изменение характеристик демпфирующих прокладок при изменении их толщины, размеров и нагрузок при расчете по ЭСПРИ-2018 приведены в таблице 1 .

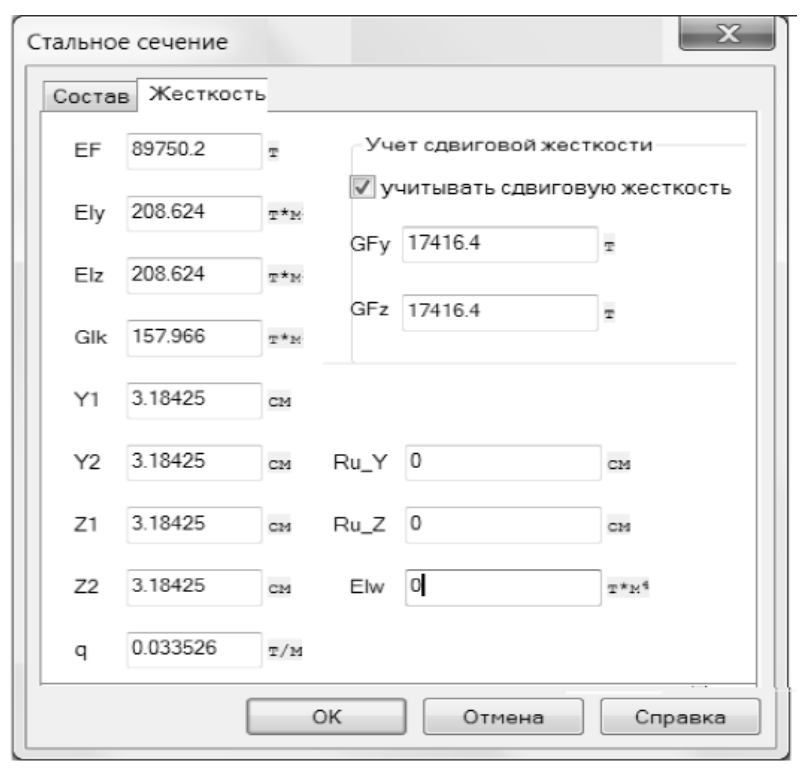

Рис.2 Жесткостные характеристики стоек из трубы диаметром 146x10мм

Для моделирования принята труба безшовная диаметром 146х10 по ГОСТ 8732-78. Схеме МКЭ выполнена в ПК "ЛИРА САПР-2019", модель состоит из стоек высотой 3м: вариант-1 без демпферных прокладок; вариант-2 резиновая прокладка толщиной 2см; вариант-3 резиновая прокладка толщиной 3cм. Нагрузка приложена на высоте $1.5 \mathrm{M}$, с массой удара в 2.0кН по направлению $\mathrm{X}$, ускорение $0.1 \mathrm{G}$.

Жесткостные характеристики металлических стоек приведено на Рис.2

На рис.3, рис.4 приведены варианты деформаций металлической стойки при статических и динами-

Табл.2 Деформации и реакции металлической стойки при статическом воздействии

\begin{tabular}{|l|c|c|c|c|}
\hline Варианты & $\begin{array}{c}\text { Реакция на } \\
\text { стойку } \\
\mathrm{Rx}(\kappa \mathrm{H})\end{array}$ & $\begin{array}{c}\text { Перемещения } \\
\text { в центре } \\
\text { (мм) }\end{array}$ & $\begin{array}{c}\text { Процент } \\
\text { демпфирования } \\
\text { реакций }\end{array}$ & $\begin{array}{c}\text { Процент } \\
\text { уменьшения } \\
\text { перемещений }\end{array}$ \\
\hline 1. без демпфера & 2.0 & -0.5480 & 0 & 0 \\
\hline 2. демпфер 2cм & 1.80605 & -0.053135 & 9.698 & 90.304 \\
\hline 3. демпфер 3см & 1.55350 & -0.122323 & 22.325 & 77.68 \\
\hline
\end{tabular}


Табл.3. Деформации и реакции металлической стойки при динамическом воздействии

\begin{tabular}{|l|c|c|c|c|}
\hline Варианты & $\begin{array}{c}\text { Реакция на } \\
\text { стойку } \\
\text { Rx (кH) }\end{array}$ & $\begin{array}{c}\text { Перемещения } \\
\text { в центре } \\
\text { (мм) }\end{array}$ & $\begin{array}{c}\text { Процент } \\
\text { демпфирования } \\
\text { реакций }\end{array}$ & $\begin{array}{c}\text { Процент } \\
\text { уменьшения } \\
\text { перемещений }\end{array}$ \\
\hline 1. без демпфера & 2.0 & -0.501630 & 0 & 0 \\
\hline 2. демпфер 2cм & 1.67729 & -0.0493465 & 16.136 & 98.37 \\
\hline 3. демпфер 3cм & 1.43849 & -0.113267 & 28.075 & 77.68 \\
\hline
\end{tabular}

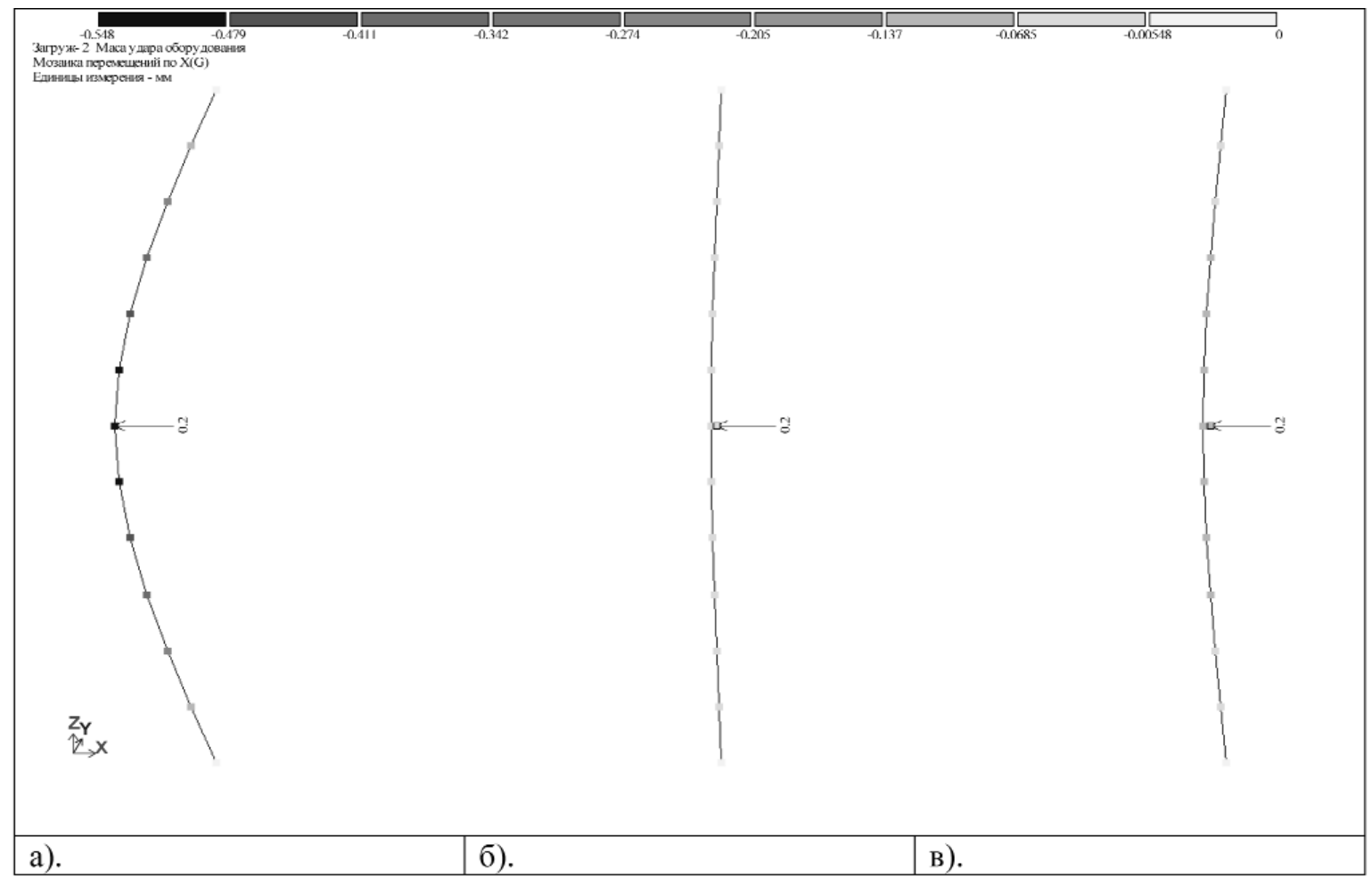

Рис.3. Варианты деформаций металлической стойки при статическом моделировании удара а). без демпфера б). демпфер толщиной $2 \mathrm{~cm} \mathrm{в).} \mathrm{демпфер} \mathrm{толщиной} 3 \mathrm{~cm}$

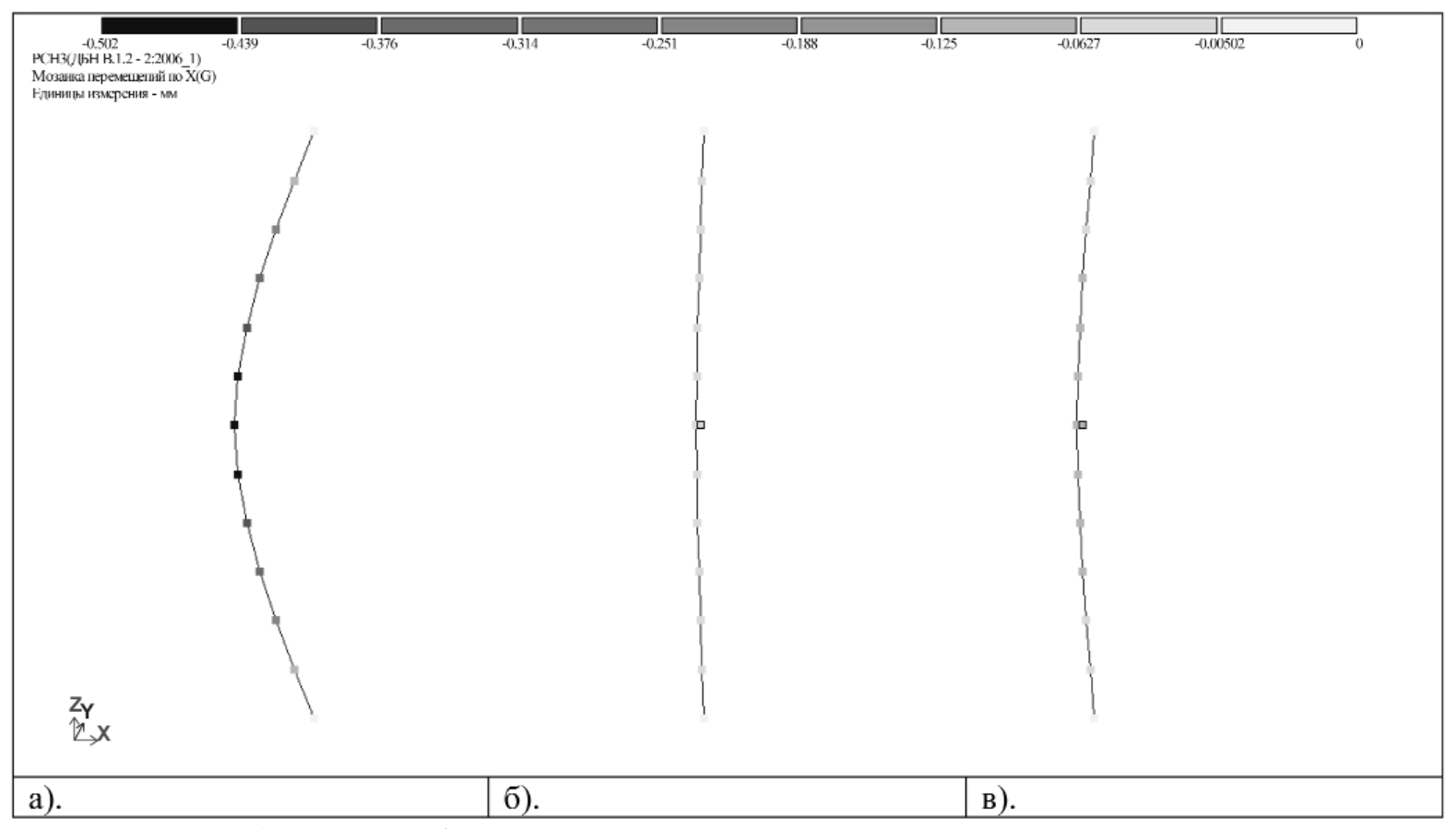

Рис.4. Варианты деформаций металлической стойки при динамическом воздействии.

а). без демпфера б). демпфер толщиной 2см в). демпфер толщиной 3см (РСH-3 П+Д+Сх) 
ческих нагружениях (спектральный метод по ДБН B.1.1-12:2014) при ускорении 0.2G.

По приведенных в Табл.2-3 результатах можно сделать выводы, что при использовании демпфирующих прокладок - сейсмические реакции на стойку уменьшаются более чем на 20\% при прокладке в
Зсм и уменьшении перемещений более 75\%.

Выводы. Результаты проведенного вариантного анализа вых (силиконовых и др.) демпферных прокладок для уменьшения сейсмических воздействий на элементы оборудования в атомных и тепловых станциях.

\section{Jumepamypa}

1. ДБН В.1.2-14:2018 Загальні принщипи забезпечення надійності та конструктивної безпеки будівель $і$ споруд.

2. Посох В.О., Инюшев В.В., Колядюк А.С., Кошмак А.С., Дубковский В.О. Вплив проектних режимів експлуатації енергоблока на циклічну міцність опорних елементів реактора ВBEP-1000//Science of Europe, No 52 (2020), том 2.C.49-55.

3. Городецький О.С., Максименко В.П., Стрелеи-Стрелецкий Е.Б, Гереймович Ю.Д. і інші. ЭСПРИ - электронный справочник инженера. Науково-техн. Журнал "Нові технологї в будівництві". №2(20). Київ. НДІБВ. 2010. С.55-68

\section{References}

1. DBN B.1.2-14 General principles of ensuring the reliability and structural safety of buildings and structures. Ukraine, 2018. 2. Posokh V.O., Injushev V. V., Kolyaduk A.C. Koshmak A.C., Dubkovsky V.O. Influence of design modes of power unit operation on cyclic strength of WWER-1000 reactor support elements//Science of Europe, No 52 (2020), moм 2.- C.49-55.

3. Gorodetsky O.S., Maksymenko V.P. Strelets-Streletsky E.B. other ESPRI - electronic engineer's directory//Scientific and technical Magazine "New technologies in construction", №2(20), Kyiv, NDIBV, 2010, p.55-68.

В.П. Максименко, к.т.Н., ДП НДІБВ, м. Київ;

В.А. Крицький, к.т.н., ГНТЦ ЯРБ;

в.о. Посох, ведучий інж., ДП "ДНИЦ СКАР"

\section{ОЦІНКА ЕФЕКТИВНОСТІ РЕЗИНОВИХ ДЕМПФЕРІВ ПРИ ЗІТКНЕННІ ЕЛЕМЕНТІВ ОБЛАДНАННЯ}

Анотація. Проведено оцінку ефективності використання гумових демпферів для зменшення сейсмічних впливів на елементи обладнання. Жорсткістні характеристики гумових демфіруючих прокладок визначені за допомогою програми "Характеристики резино-металевого демпфера" в ЕСПРІ-2018.

Ключові слова: гумові демпфери.

V.P. Maksimenko, Ph.D, State Enterprise "Research institute of building production named V.S. Balitsky", Kyiv;

V.A. Kricky, Ph.D, GNTC;

V.O. Posoh, GP DNIC SKAR

\section{ESTIMATION OF THE EFFICIENCY OF RUBBER DAMPER AT COLLISION OF EQUIPMENT ELEMENTS}

Annotation. Evaluation of the effectiveness of using rubber dampers to reduce seismic effects on equipment elements.

The stiffness characteristics of rubber damping pads were determined using the program "Characteristics of a rubber-metal damper" in ESPRI-2018.

Keyzords: rubber dampers. 